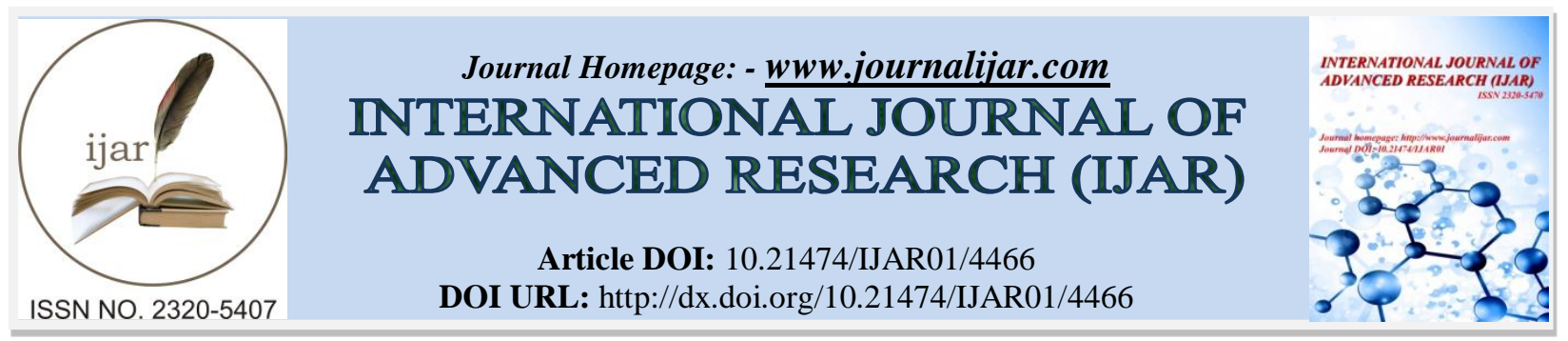

RESEARCH ARTICLE

\title{
AN IMPORTANCE-PERFORMANCE ANALYSIS (IPA) FOR ASSESSMENT OF ABSORPTIVE CAPACITY: THE CASE OF MOBILE-COMMUNICATION COMPANY OF IRAN (MCI)
}

\author{
Hamidreza Radmanesh, Mohsen Behdari, Nasrin Aghaee, Negar Rastegar and Mohammadreza Asadzadeh. \\ MBA Student, Linköping University.
}

\section{Manuscript Info}

Manuscript History

Received: 13 April 2017

Final Accepted: 15 May 2017

Published: June 2017

Key words:-

Absorptive Capacity (ACAP),

competitive advantage, innovative

capabilities, Importance-Performance

Analysis (IPA)

\section{Abstract}

This study aims to review the concept of absorptive capacity (ACAP) and then assess MCI from this perspective, whereas there is not any literature related to assessment of ACAP for a mobile network operator. In this regard two questions were developed: What are absorptive capacity dimensions? In which dimension(s) should MCI concentrate? So, the dimensions of ACAP assessment were found through study the literature and then a quantitative study was conducted through sending a questionnaire to employees of MCI. The authors found that MCI has big gap in all of dimensions. So to improve prioritization, importance-performance analysis was utilized.

Copy Right, IJAR, 2017,. All rights reserved.

\section{Introduction:-}

Firms are intercommunicating more and more with outside partners to achieve external knowledge. Such a knowledge enables them to innovate and stand competitive in the market. To apply external knowledge, they must have a distinctive capacity to absorb knowledge (Zerwas, 2014).

To attain competitive advantage, Innovativeness is necessary. Absorptive capacity (ACAP) is one essential factor of innovativeness and thereby competitive advantage (Ince et al., 2016, de Mello et all, 2008). Absorptive capacity is addressed as a one of the dynamic capabilities of businesses (Lawer, 2010). In other words, dynamic capabilities include innovative capability, adaptive capability and absorptive capability (Wang and Ahmed, 2007). It should be mentioned that the terms absorptive capacity and absorptive capability are used as synonyms (Saeedi, 2014). Also, in some literatures Absorptive capacity (ACAP) is considered as a component of innovative capabilities (Cohen and Levinthal, 1990).

MCI as an incumbent mobile operator in Iran, among the competition attempts to maintain its dominant share of the market. To realize this aim, this company should pay enough attention to its competitive advantage and innovative capabilities. So, in this situation an assessment on absorptive capacity (as a component of innovative capabilities) is necessary.

\section{Theoretical background:-}

Absorptive Capacity (ACAP):-

ACAP initially conceptualized by Cohen and Levinthal. They defined ACAP as "a firm's ability to recognize the value of new information, assimilate it, and apply it to commercial ends." (Cohen and Levinthal, 1990). The ability to evaluate external knowledge is related to firm's previous experience and former funding (Kausch, 2007). Before 
Cohen and Levinthal, this term had been mentioned by Kedia \& Bhagat (1988). They discuss about technology transfer between different organizational cultures.

From this point of view firms are divided to two categories (Guedes et al., 2017):

- Proactive Firms: They have the highest level of absorptive capacity.

- Reactive Firms: They have little absorptive capacity

The significance of ACAP has been mentioned in many areas such as strategic management, technology management, international business and organizational economics (Zahra \& George, 2002).

Cohen \& Levinthal (1990) constructed a model with three dimensions:

- Acknowledgement of the value of information

- Assimilation of that knowledge by the firm

- Application to enhance innovation

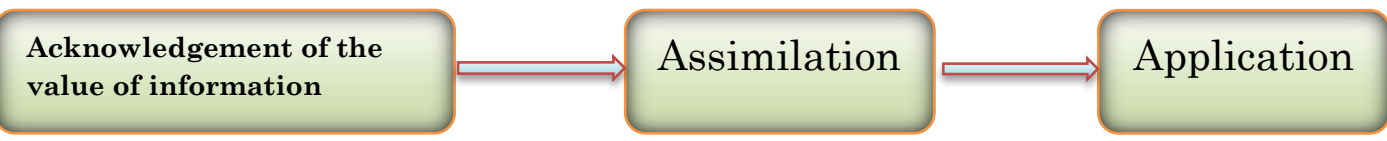

Figure 1:- Model of absorptive capacity (Cohen and Levinthal, 1990).

They also realized that prior knowledge consists of personnel attributes and innovative practices.

The first extension on above model was developed by Lane \& Lubatkin (1998). They consider ACAP as "studentteacher" relation between firms and discuss on three needed similarities to succeed in this regard. These three similarity items are:

$>$ Knowledge bases

$>$ Organizational structures and compensation policies

$>$ Dominant logics

Zahra \& George (2002) developed a concept that enlarge the Cohen \& Levinthal (1990) model. It divides absorptive capacity into two basic dimensions: potential and realized. So, after acknowledgement of the important information, it needs to be incorporated and transformed and may therefore be exploited. Therefore, the capabilities are dynamic (interactive and changeable).

After that Todorova \& Durisin (2007) suggested to return to the original model of Cohen \& Levinthal (1990) with a new explanation as illustrated in Figure 2.

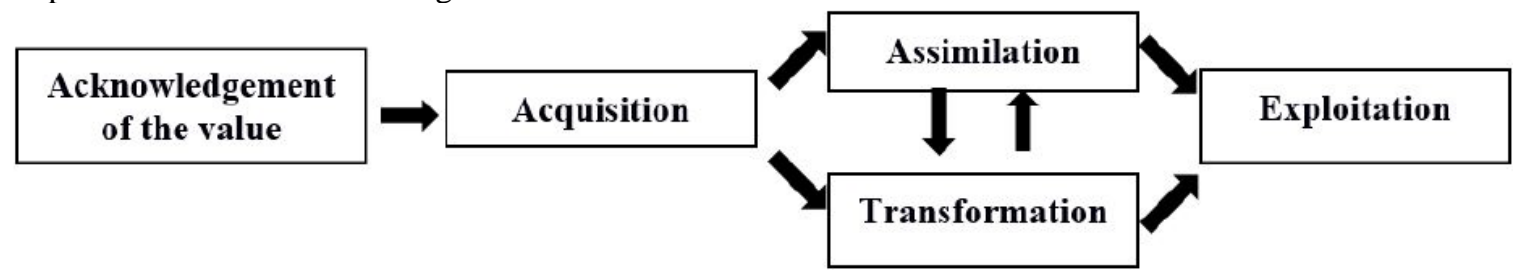

Figure 2:- Model of ACAP (Todorova \& Durisin, 2007).

According to Vega-Jurado et al. (2008), ACAP is specified not only by R\&D activities, but also by a set of internal factors, which can be classified to:

$>$ Organizational knowledge

$>$ Formalization

$>$ Social integration mechanisms

Figure 3 illustrates the model related to these factors and their impact on all components of the company's ACAP. 


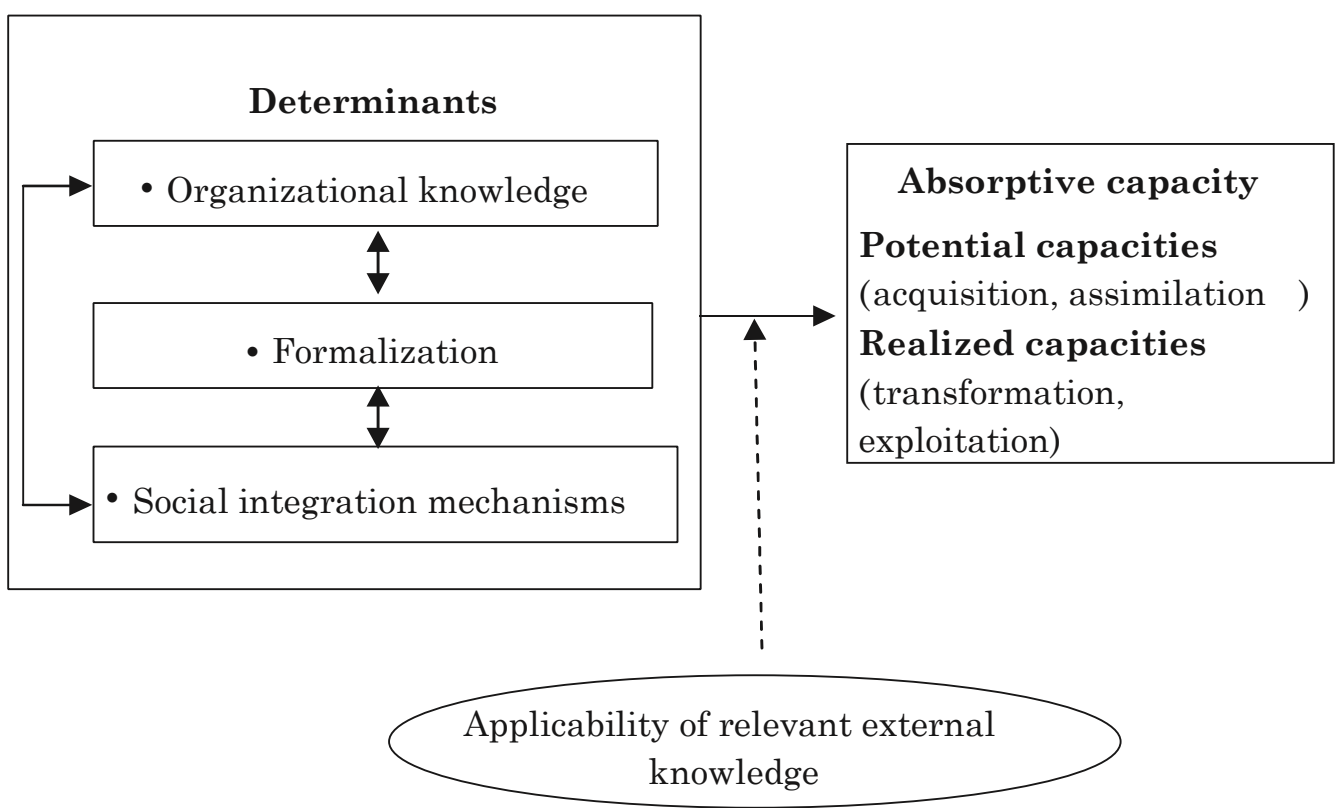

Figure 3:- ACAP Model (Vega-Jurado et al., 2008).

\section{Based on Murovec \& Prodan (2009) ACAP is divided into two categories:}

$>$ Industrial ACAP (or demand-pull): It is the acquisition of knowledge from industrial partners (customers, competitors and suppliers)

$>$ Scientific ACAP (or science-push): knowledge is acquired from universities, technology institutes and public and private research centers.

\section{Conceptual model for ACAP:-}

According to Zahra \& George's (2002), ACAP dimensions are (Figure 4):

$>$ Potential capacities (acquisition, assimilation)

$>$ Realized capacities (transformation, exploitation)

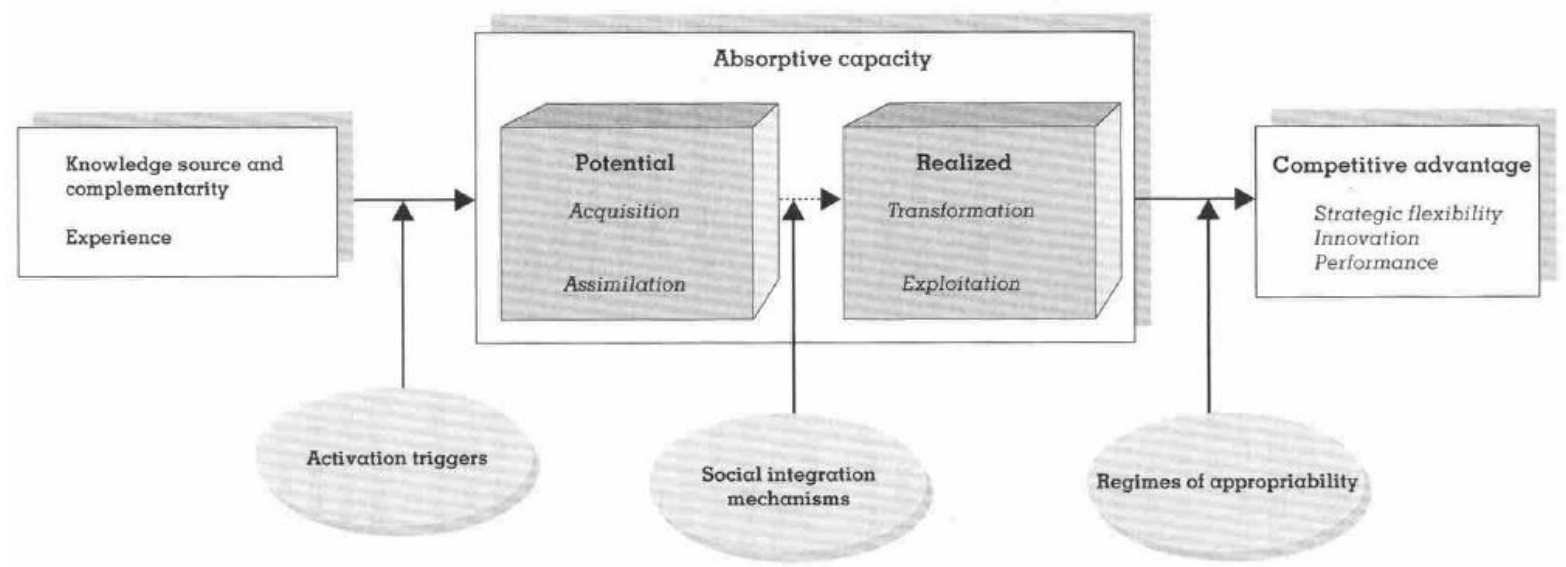

Figure 4:- A model of ACAP (Zahra \& George,2002) 
The description of these dimensions are listed in Table 1:

Table 1:- ACAP dimensions description (Zahra \& George, 2002)

\begin{tabular}{|c|c|c|}
\hline $\begin{array}{l}\text { ACAP } \\
\text { Dimension }\end{array}$ & Description & $\begin{array}{l}\text { Sub-components of } \\
\text { Dimension }\end{array}$ \\
\hline Acquisition & $\begin{array}{l}\text { Acquisition refers to a firm's capability to identify and } \\
\text { acquire externally generated knowledge that is critical to } \\
\text { its operations. }\end{array}$ & $\begin{array}{l}\text { - } \text { Prior investments } \\
\text { - } \text { Intensity of connections } \\
\text { - } \text { Direction of knowledge }\end{array}$ \\
\hline Assimilation & $\begin{array}{l}\text { Assimilation refers to the firm's routines and processes } \\
\text { that allow it to analyze, process, interpret, and } \\
\text { understand the information obtained from external } \\
\text { sources }\end{array}$ & $\begin{array}{l}\text { - Understanding of external } \\
\text { acquired knowledge }\end{array}$ \\
\hline Transformation & $\begin{array}{l}\text { Transformation denotes a firm's capability to develop } \\
\text { and refine the routines that facilitate combining existing } \\
\text { knowledge and the newly acquired and assimilated } \\
\text { knowledge. }\end{array}$ & $\begin{array}{l}\text { - Internalization } \\
\text { sharing } \\
\text { - Knowledge integration }\end{array}$ \\
\hline Exploitation & $\begin{array}{l}\text { Exploitation as an organizational capability is based on } \\
\text { the routines that allow firms to refine, extend, and } \\
\text { leverage existing competencies or to create new ones by } \\
\text { incorporating acquired and transformed knowledge into } \\
\text { its operations }\end{array}$ & $\begin{array}{l}\text { Application and implementation of } \\
\text { knowledge to commercial ends }\end{array}$ \\
\hline
\end{tabular}

Importance-Performance Analysis (IPA):-

In order to improve firm performance, Matrilla and James (1977) introduced Importance-Performance Analysis (IPA) as a beneficial tool to conceptualize identifying firm strengths and weaknesses. This tool can be used during defining a strategy or evaluating it (Lai \& To, 2010).

IPA is an analytical method which make "a two-dimensional importance-performance grid, where the values of importance and performance across attributes are plotted against each other". When resources are limited for improvement, this method is used to help firms in prioritizing areas (Feng et al., 2014).

The Importance-Performance Analysis model is divided to four quadrants by considering "y-axis: importance" and "x-axis: performance" (Chen\& Lin, 2013). Each quadrant has meaning which has been specified in Figure 5. 


\section{Importance}

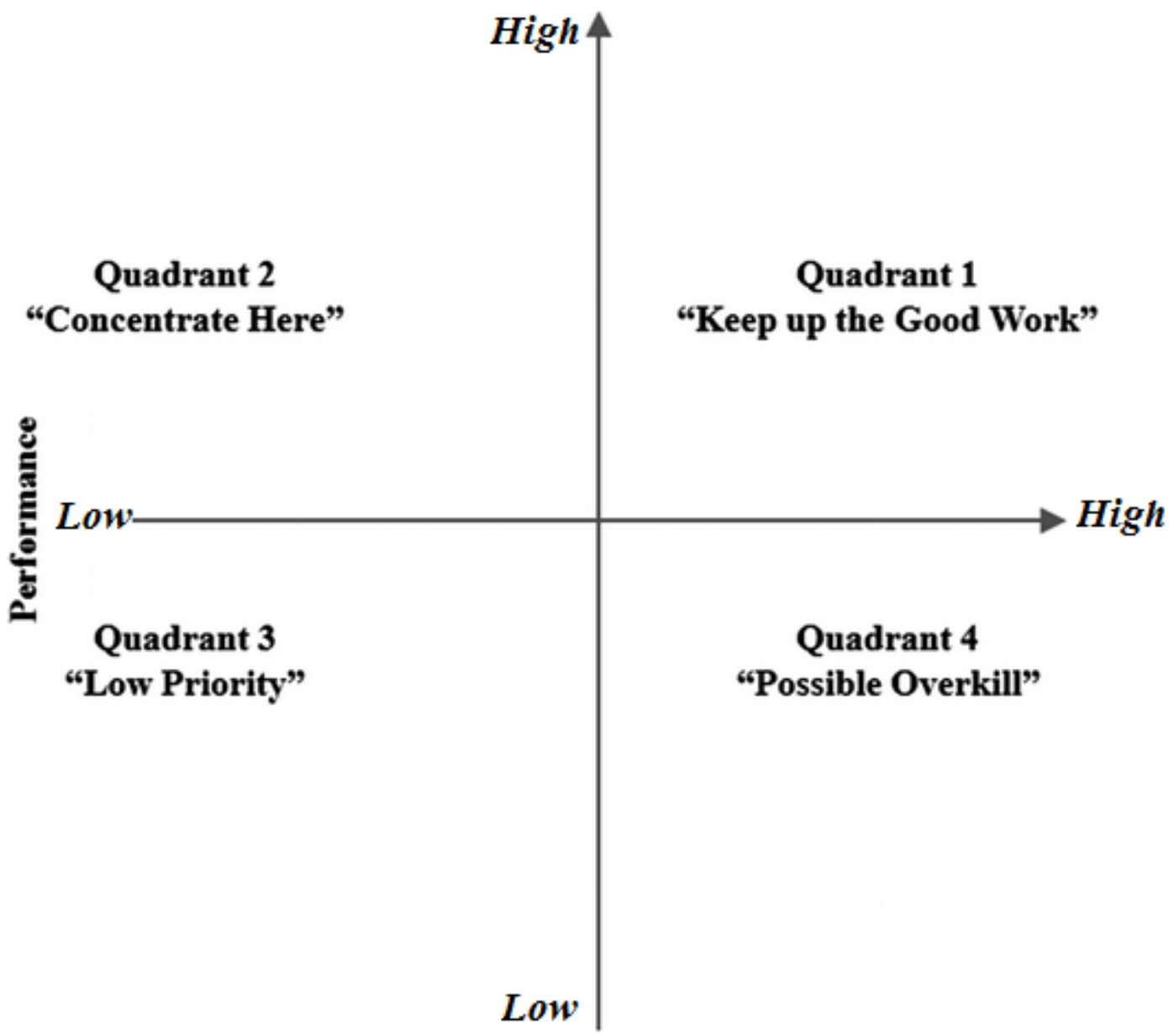

Figure 5:- IPA model (Matrilla and James, 1977)

Method:-

The "survey" strategy for this research has been selected through deductive approach. As mentioned in previous part, many studies after 2000, considered above-mentioned four dimensions for ACAP in their model. There are many available questionnaires in the literature in this regard. But Flatten et al. (2011) did a comprehensive study to pool the statements of the questionnaire and screening them to find the most complete and most accurate one. So, to assess ACAP, final ACAP scale in Flatten et al. (2011) has been selected. (table 2) 
Table 2:- Final ACAP scale (Flatten et al., 2011)

\section{Acquisition}

Please specify to what extent your company uses external resources to obtain information (e.g., personal networks, consultants, seminars, internet, database, professional journals, academic publications, market research, regulations, and laws concerning environment/technique/health/security):

Acquisition 1

Acquisition 2

The search for relevant information concerning our industry is every-day business in our company.

Acquisition 3

Our management motivates the employees to use information sources within our industry.

Our management expects that the employees deal with information beyond our industry.

Assimilation

Please rate to what extent the following statements fit the communication structure in your company:

Assimilation $1 \quad$ In our company ideas and concepts are communicated cross-departmental.

Assimilation 2 Our management emphasizes cross-departmental support to solve problems.

Assimilation 3 In our company there is a quick information flow, e.g., if a business unit obtains important information it communicates this information promptly to all other business units or departments.

Assimilation $4 \quad$ Our management| demands periodical cross-departmental meetings to interchange new developments, problems, and achievements.

Transformation

Please specifv to what extent the following statements fit the knowledge processing in your company:

Transformation 1

Transformation 2

Our employees have the ability to structure and to use collected knowledge.

Our employees are used to absorb new knowledge as well as to prepare it for further purposes and to make it available.

Transformation $3 \quad$ Our employees successfully link existing knowledge with new insights.

Transformation $4 \quad$ Our employees are able to apply new knowledge in their practical work.

Exploitation

Please specify to what extent the following statements fit the commercial exploitation of new knowledge in your company (NB: Please think about all company divisions such as R\&D, production, marketing, and accounting):

Exploitation $1 \quad$ Our management supports the development of prototypes.

Exploitation 2 Our company regularly reconsiders technologies and adapts them accordant to new knowledge.

Exploitation $3 \quad$ Our company has the ability to work more effective by adopting new technologies.

To provide questionnaire above statements were translated to Farsi (Persian Language). For each statement both of importance and performance were inquired. A Likert scale (1 to 5) has been used. The questionnaire was developed by Google Form. 192 electronic questionnaires (the URL link of Google Form) were distributed by email to MCI employees to provide the primary data. By some following up from the employees, 113 valid responses obtained.

When the data gathered, to analysis it, SPSS and EXCEL software used and some calculations such as MEAN, Standard Deviations and Gap scores was performed. In addition, Cronbach's alpha coefficient calculated to consider the reliability of statements.

\section{Data Analysis and Discussion:-}

As mentioned 113 valid responses were obtained from MCI employees (Response Rate=59\%). Some demographic profiles of the sample are summarized in Table 3.

Table 3:- Demographic Profiles.

\begin{tabular}{|c|l|l|l|l|}
\hline \multirow{4}{*}{ Age } & Under 30 & 30 to 40 & Above 40 & \\
\cline { 2 - 5 } & 28 & 68 & 17 & \\
\cline { 2 - 5 } & $24.78 \%$ & $60.18 \%$ & $15.04 \%$ & \\
\hline \multirow{5}{*}{ Gender } & Male & Female & & \\
\cline { 2 - 5 } & 54 & 59 & & \\
\cline { 2 - 5 } & $47.79 \%$ & $52.21 \%$ & MSc & PHD \\
\hline \multirow{3}{*}{ Education } & Associate Degree & BSc & 62 & 1 \\
\cline { 2 - 5 } & 4 & 46 & $54.87 \%$ & $0.88 \%$ \\
\cline { 2 - 5 } & $3.54 \%$ & $40.71 \%$ & & \\
\hline
\end{tabular}

After data gathering, for each statement, average of Importance and average of Performance and related GAP were calculated. Also for each dimension, Importance, Performance and Gap were calculated by averaging from related statements (Table 4). 
Table 4:- Importance-Performance Result of ACAP Assessment.

\begin{tabular}{|c|c|c|c|c|c|c|c|}
\hline & & \multicolumn{3}{|c|}{ Statements } & \multicolumn{3}{|c|}{ Dimensions } \\
\hline ACAP Dimension & Statements & Importance & Performance & GAP & Importance & Performance & GAP \\
\hline \multirow{3}{*}{ Acquisition } & Acquisition1 & 4.614 & 2.686 & 1.928 & \multirow[t]{3}{*}{4.475} & \multirow[t]{3}{*}{2.398} & \multirow[t]{3}{*}{2.077} \\
\hline & Acquisition2 & 4.656 & 2.354 & 2.302 & & & \\
\hline & Acquisition3 & 4.155 & 2.153 & 2.002 & & & \\
\hline \multirow[t]{4}{*}{ Assimilation } & Assimilation1 & 4.727 & 1.869 & 2.858 & \multirow[t]{4}{*}{4.755} & \multirow[t]{4}{*}{1.705} & \multirow[t]{4}{*}{3.050} \\
\hline & Assimilation2 & 4.937 & 1.690 & 3.247 & & & \\
\hline & Assimilation3 & 4.678 & 1.753 & 2.925 & & & \\
\hline & Assimilation4 & 4.680 & 1.508 & 3.172 & & & \\
\hline \multirow[t]{4}{*}{ Transformation } & Transformation1 & 4.501 & 1.962 & 2.539 & \multirow[t]{4}{*}{4.565} & \multirow[t]{4}{*}{1.814} & \multirow[t]{4}{*}{2.751} \\
\hline & Transformation2 & 4.521 & 1.997 & 2.524 & & & \\
\hline & Transformation3 & 4.748 & 1.847 & 2.901 & & & \\
\hline & Transformation4 & 4.489 & 1.448 & 3.040 & & & \\
\hline \multirow[t]{3}{*}{ Exploitation } & Exploitation1 & 3.959 & 1.412 & 2.547 & \multirow[t]{3}{*}{4.270} & \multirow[t]{3}{*}{2.066} & \multirow[t]{3}{*}{2.204} \\
\hline & Exploitation2 & 4.283 & 2.282 & 2.001 & & & \\
\hline & Exploitation3 & 4.568 & 2.503 & 2.064 & & & \\
\hline Average & & 4.537 & 1.962 & & & & \\
\hline
\end{tabular}

As mentioned the questionnaire design based on Flatten et al. (2011). These statements are valid because result shows the high correlation (0.87) based on Cronbach's Alpha.

In order to have more accurate perioritizing and provide better decsion making cretaria, instead of sipmle GAP, IPA method was ussed for assessment. According to results in Figure 6 and Figure 7, the more periority gaps are marked by red colour. It should be mentioned if we consider gap score, Transformation4 statement has higher value for gap score in comparison to Transformation3, Assimilation1 and Assimilation3 statements. So, in this situation IPA model indicates there is low periority to resolve Transformation4 statement althogh its gap score is high.

\section{Importance}

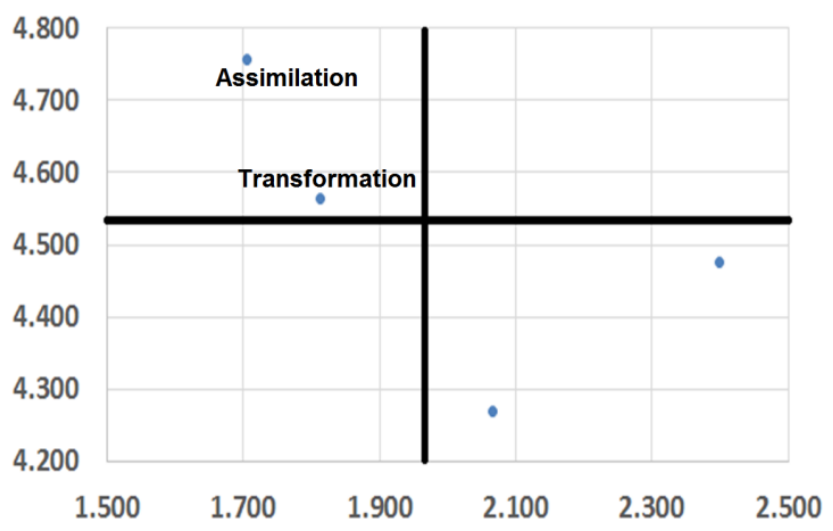

Figure 6:- IPA model for Dimensions of ACAP Assessment. 


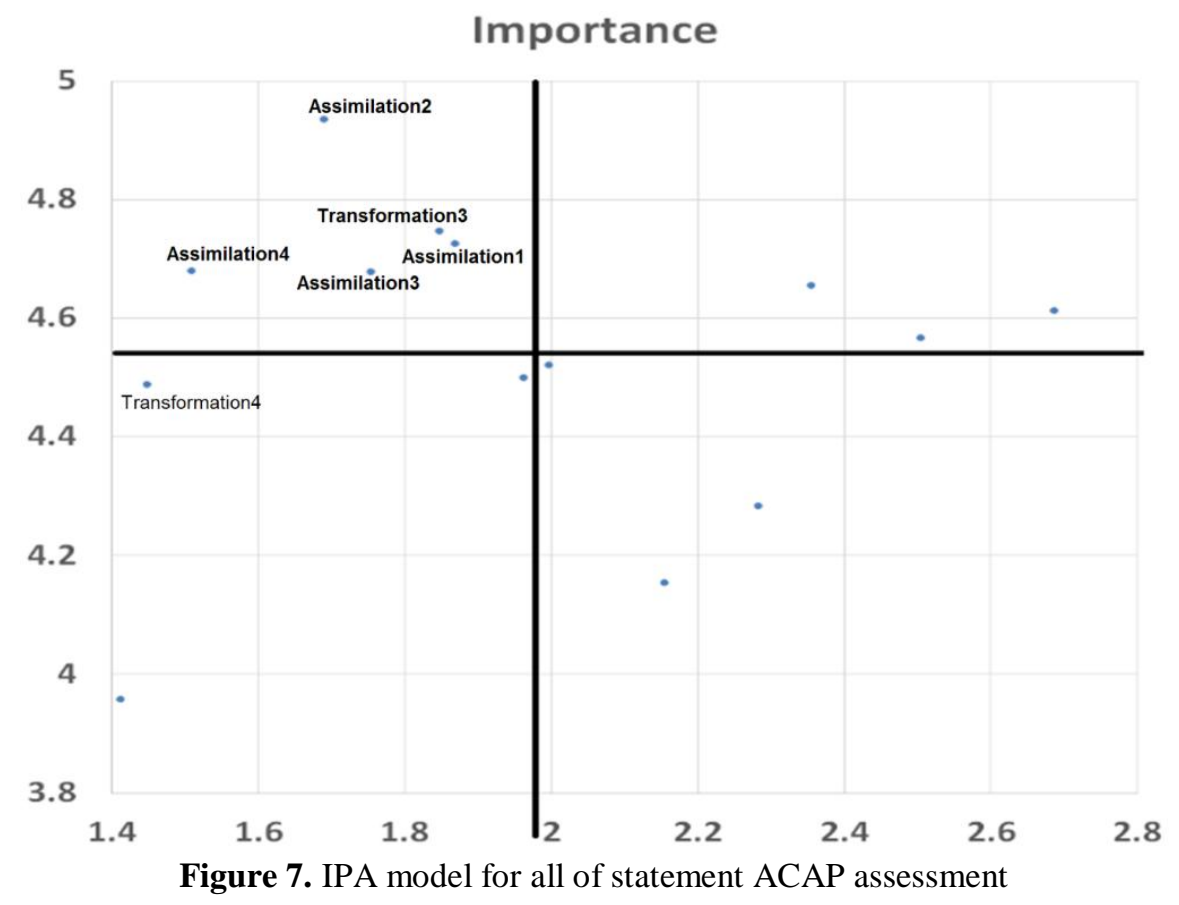

\section{Conclusion:-}

In this research, after review on literature, the dimensions absorptive capacity (ACAP) have been extracted as acquisition, assimilation, transformation and exploitation. Then MCI's ACAP as an essential factor of innovativeness was assessed. In this regard final ACAP scale in Flatten et al. (2011) was selected and the questionnaire was distributed to MCI's employees. According to IPA model, MCI should cocentrate on assimilation and transformation dimensions. The problem in assimilation dimension is related to cross-departemental (communication/ meeting/ support) and information flow. The problem in transformation dimension is related to create linkage between knowledge and insights. So to resolve these problems corrective actions such as improving collabotatin culture, impovering infrastructure (and commitment to use them) and some training program is needed.

\section{References:-}

1. Chen, Y. C., \& Lin, S. (2013). Applying importance-performance analysis for improving internal marketing of hospital management in Taiwan. International Business Research, 6(4), 45.

2. Cohen, W. M., \& Levinthal, D. A. (1990). Absorptive capacity: A new perspective on learning and innovation. Administrative science quarterly, 128-152.

3. de Mello, A. M., de Lima, W. D., Boas, E. V., Sbragia, R., \& Marx, R. (2008, July). Innovation capability and competitive advantage: A case study of two Brazilian Firms. In Management of Engineering \& Technology, 2008. PICMET 2008. Portland International Conference on (pp. 606-617). IEEE.

4. Feng, M., Mangan, J., Wong, C., Xu, M., \& Lalwani, C. (2014). Investigating the different approaches to importance-performance analysis. The Service Industries Journal, 34(12), 1021-1041.

5. Flatten, T. C., Engelen, A., Zahra, S. A., \& Brettel, M. (2011). A measure of absorptive capacity: Scale development and validation. European Management Journal, 29(2), 98-116.

6. Guedes, H. D. P., Ziviani, F., Paiva, R. V. C. D., Ferreira, M. A. T., \& Herzog, M. D. M. (2017). Assessment of absorptive capacity: a study in Brazilian manufactures of solar panels. Gestão \& Produção, 24(1), 50-63.

7. Ince, H., Imamoglu, S. Z., \& Turkcan, H. (2016). The Effect of Technological Innovation Capabilities and Absorptive Capacity on Firm Innovativeness: A Conceptual Framework. Procedia-Social and Behavioral Sciences, 235, 764-770.

8. Kausch, C. (2007). A risk-benefit perspective on early customer integration (No. 3298). Springer Science \& Business Media.

9. Kedia, B. L., \& Bhagat, R. S. (1988). Cultural constraints on transfer of technology across nations: Implications for research in international and comparative management. Academy of Management Review, 13(4), 559-571.

10. Lai, L. S., \& To, W. M. (2010). Importance-performance analysis for public management decision making: An empirical study of China's Macao special administrative region. Management Decision, 48(2), 277-295. 
11. Lane, P. J., \& Lubatkin, M. (1998). Relative absorptive capacity and interorganizational learning. Strategic management journal, 461-477.

12. Lawer, C. (2010). How does absorptive capacity influence the origin and evolution of dynamic capabilities.

13. Martilla, J. A., \& James, J. C. (1977). Importance-performance analysis. The journal of marketing, 77-79.

14. Murovec, N., \& Prodan, I. (2009). Absorptive capacity, its determinants, and influence on innovation output: Cross-cultural validation of the structural model. Technovation, 29(12), 859-872.

15. Saeedi, M. R. (2014). Fostering Dynamic Capabilities of SMEs. The Impact of Inward International Licensing on Absorptive Capacity and Networking Capability: A Multiple Case Study in Pharmaceutical Industry (Doctoral dissertation, Linköping University Electronic Press).

16. Vega-Jurado, J., Gutiérrez-Gracia, A., \& Fernández-de-Lucio, I. (2008). Analyzing the determinants of firm's absorptive capacity: beyond R\&D. R\&d Management, 38(4), 392-405.

17. Wang, C. L., \& Ahmed, P. K. (2007). Dynamic capabilities: A review and research agenda. International journal of management reviews, 9(1), 31-51.

18. Zahra, S. A., \& George, G. (2002). Absorptive capacity: A review, reconceptualization, and extension. Academy of management review, 27(2), 185-203.

19. Zerwas, D. (2014). Organizational Culture and Absorptive Capacity: The Meaning for SMEs. Springer Science $\&$ Business Media. 